\title{
ANALISIS KETERLAMBATAN PENGEMBALIAN BERKAS REKAM MEDIS RAWAT JALAN DI RSUP Dr. HASAN SADIKIN
}

\author{
Ridwan Cahya Sunardi ${ }^{1}$, Fahrul Rizal Pahlepi ${ }^{2 *}$, Meira Hidayati ${ }^{3}$ \\ Politeknik Piksi Ganesha, Indonesia ${ }^{1,2,3}$ \\ cahyaaalam94@gmail.com ${ }^{1}$, piksi.fahrul.18303136@gmail.com²*, \\ meirahidayati58@gmail.com ${ }^{3}$
}

Received: 19-08-2021

Revised : 12-09-2021

Accepted: 24-09-2021

\begin{abstract}
Abstrak
Latar Belakang: Keterlambatan pengembalian berkas Rekam Medis Pasien Rawat Jalan dapat menghambat proses pengelolaan Rekam Medis dan Pelayanan Rawat Jalan Di RSUP Dr. Hasan Sadikin Bandung. Standar Pengembalian berkas rekam medis rawat jalan di Rumah Sakit Dr. Hasan Sadikin Bandung adalah segera setelah segera setelah pelayanan atau 1 x24 jam.
\end{abstract}

Tujuan: Tujuan penelitiaan ini adalah ingin mangetahui lebih dalam tentang pengembalian rekam medis rawat jalan apakah sudah sesuai standar oprasional prosedur yang berlaku di RSUP Dr. Hasan Sadikin

Metode: Metode penelitian menggunakan metode kuantitatif dengan pendekatan deskriptif. Teknik sampel yang di gunakan adalah teknik simple random sampling dengan jumlah sample 100 berkas rekam medis rawat jalan dari total kunjungan pasien rawat jalan sebanyak 12461 pada bulan juni 2021.

Hasil: Dari hasil penelitian penulis terjadi ketidaksesuaian standar oprasional prosedur yang berlaku di RSUP Dr. Hasan Sadikin, dimana terjadi keterlambatan pengembalian rekam medis yang seharusnya dikembalikan 1x24jam ternyata penelitian menunjukan bahwa keterlambatan pengembalian rekam medis terendah pada tgl $2 \mathrm{~s} / \mathrm{d} 14$ Juni 2021 sebanyak 30 berkas rekam medis (60\%) dan keterlambatan pengembalian berkas rekam medis tertinggi pada tgl 15 s/d 30 Juni 2021 sebanyak 36 berkas rekam medis (72\%).

Kesimpulan: Ketidaksesuainya prosedur yang ada dengan pelaksanaan di lapangan masih terjadi keterlambatan pengembalian total dari keseluruhan sempel yang di ambil terjadi keterlambatan sebesar $72 \%$ dan yang terendah sebesar $60 \%$ yang dikarenakan tidak ada pengecekan terhadap rekam medis yang di pinjam dengan yang dikembalikan oleh perawat dan petugas poliklinik.

Kata kunci: keterlambatan pengambalian berkas rekam medis, kualitas pelayanan, rawat jalan.

\section{Abstract}




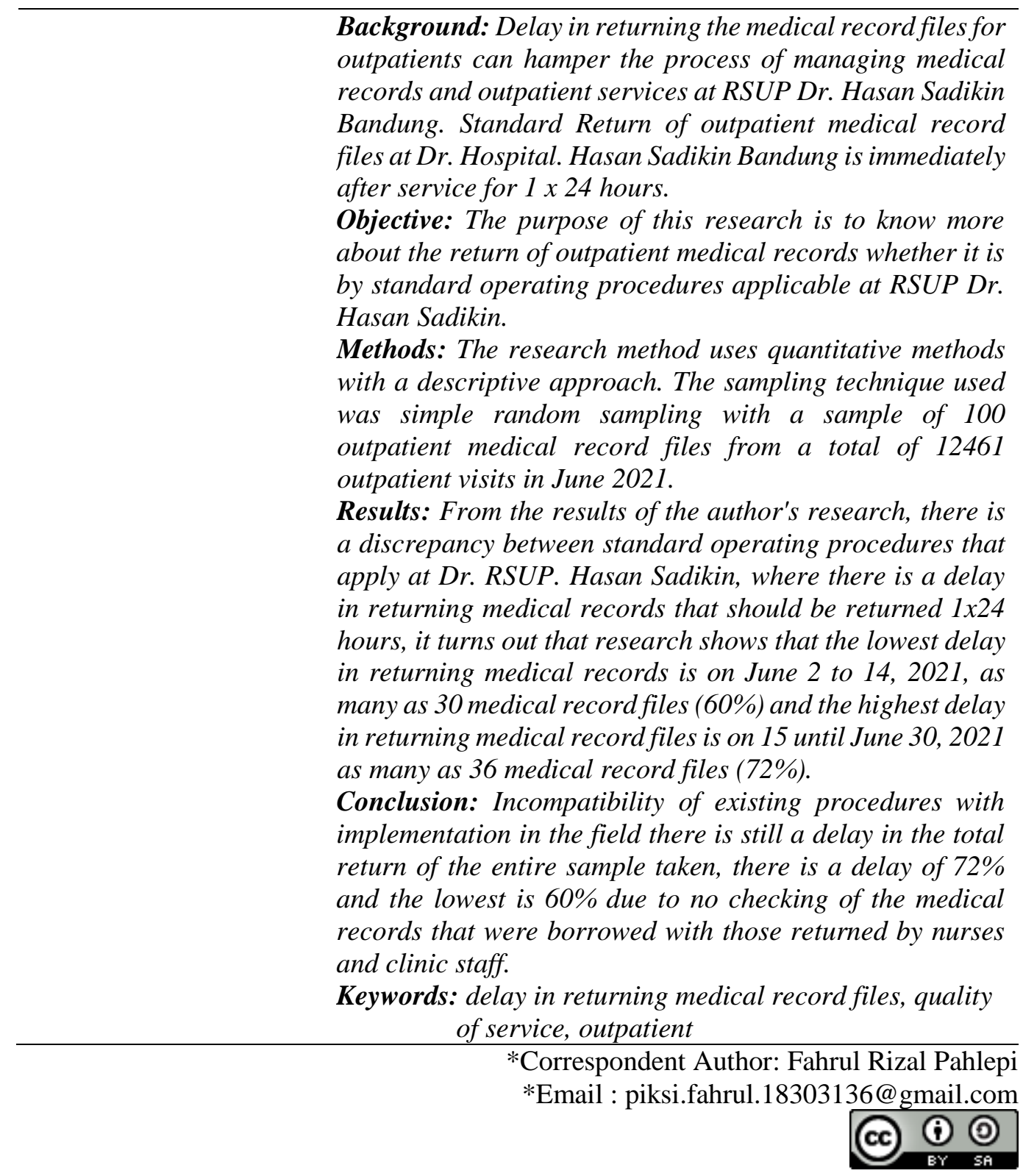

\section{PENDAHULUAN}

Rekam medis adalah berkas yang berisikan catatan dan dokumen tentang identitas pasien, pemeriksaan, pengobatan, tindakan, dan pelayanan lain yang telah di berikan kepada pasien (Permenkes, 2008). Proses pengelolaan rekam medis terdiri dari beberapa tahapan antara lain dilakukanya assembling, koding, indeksing, dan filling menurut Departmen kesehatan tahun 2006 dalam (Octaria et al., 2021)

Untuk mendapatkan kinerja instalasi rekam medis yang berkualitas maka proses penyelenggaran rekam medis harus benar dan tepat.Termasuk dalam pengembalian rekam medis (Muchtar et al., 2018). Pengembalian rekam medis adalah suatu proses pengembalian rekam medis dari unit pelayanan yang meminjam kembali ke unit rekam medis (Muhammad Thabran Talib, 2021)

Pengembalian berkas rekam medis rawat Jalan adalah suatu kegiatan penerimaan, pemeriksaan dan pengambilan berkas rekam medis pasien pulang rawat jalan dari klinik ke sub instalasi pengelolaan rekam medis rawat ialan.(Ritonga \& Wannara, 2020) 
RSUP Dr.Hasan Sadikin Bandung merupakan rumah sakit pemerintah dibawah kementrian kesehatan. Berdasarkan hasil praktek kerja lapangan di instalasi rekam medis rawat jalan masih di temukan beberapa masalah dalam pengembalian berkas rekam medis rawat jalan.

Penyebab keterlambatan pengembalian berkas rekam medis rawat jalan adalah SDM (dokter residen) (Djusmalinar, 2017). Permasalahan yang terjadi pengembalian berkas rekam medis $1 \times 24$ jam atau segera setelah pelayanan di berikan, ternyata masih sering terjadi keterlambatan pengembalian lebih dari 1x24jam. Berkas rekam medis masih menumpuk di poliklinik yang belum di lengkapi oleh dokter dan perawat. Penyebab keterlambatan pengembalian berkas rekam medis rawat jalan adalah SDM (dokter residen dan perawat). Dalam mengembalikan berkas kurang tertib dan kurangnya komunikasi dengan petugas rekam medis. Sehingga banyak berkas rekam medis masih berada di poliklinik berhari hari. Hal ini berdampak pada kualitas pelayanan.

Berdasarkan latar belakang tersebut, penulis tertarik ingin mengetahui lebih lanjut dalam hal "Analisis Keterlambatan Pengembalian Berkas Rekam Medis Rawat Jalan di RSUP Dr. Hasan Sadikin Bandung".

\section{METODE PENELITIAN}

Metode penelitian menggunakan pendekatan peneliatian kuantitatif. Penelitian deskriftif kuantitatif merupakan jenis metode penelitian yang dilakukan denga tinjauan utama untuk mendeskripsikan suatu keadaan secara obyektif (Sugiyono, 2013). Jenis penelitian ini digunakan untuk memecahkan atau menjawab permasalahan yang sedang dihadapi pada situasi tertentu. Penelitian ini dilakukan dengan menempuh langkah langkah pengumpulan data, klasifikasi, pengolahan atau analisis data, membuat kesimpulan, dan laporan.

Teknik sampling yang di gunakan pada penelitian ini adalah simple random sampling. Simple random sampling merupakan teknik pengambilan sampling dari populasi yang dilakukan secara acak tanpa memperhatikan strata yang ada dalam populasi itu. Populasi penelitian ini yaitu seluruh berkas rekam medis yang keluar berdasarkan data kunjungan pasien rawat jalan di bulan Juni yang berjumlah 12461, diolah berkas rekam medis yang terlambat dan yang tepat. Hasil penelitian ini kemudian dianalisis secara deskriptif untuk mendapatkan gambaran keterlambatan pangembalian berkas rekam medis rawat jalan. Diambil dari populasi pada penelitian ini menggunakan rumus Slovin dengan nilai $\mathrm{e}=10 \%$ adalah sebagai berikut :

$$
\begin{aligned}
n & =\frac{N}{1+N(e)^{2}} \\
n=\frac{12461}{1+12461(10 \%)^{2}}= & \frac{12461}{1+12461(0,1)^{2}}=\frac{12461}{125,61}=99,2
\end{aligned}
$$

Jadi sampel yang digunakan untuk penelitian ini sebanyak 100 berkas rekam medis.

Instrumen penelitian ini dengan teknik pengambilan data yaitu Observasi, wawancara dan studi dokumentasi. Observasi pada penelitian ini bertujuan agar lebih mengetahui secara langsung bagaimana keterlambatan pengembalian rekam medis rawat jalan di RSUP. Dr Hasan Sadikin Bandung. Wawancara sangat bermanfaat dalam mengetahui secara langsung dengan bertatap muka mengenai Analisis Keterlamabatan Pengembalian Berkas Rekam Medis Rawat Jalan di RSUP Dr. Hasan Sadikin Bandung. Studi dokumentasi dilakukan oleh penulis dengan meneliti secara langsung agar data yang di peroleh semakin kuat. Dara tersebut di peroleh dengan cara melakukan pengamatan mengenai Analisis Keterlambatan Pengembalian Berkas Rekam Medis Rawat Jalan di RSUP Dr. Hasan Sadikin Bandung. 


\section{Standar Prosedur Operasional Pengembalian Rekam Medis Rawat Jalan Ke Sub Instalasi Rekam Medis Rawat Jalan Rumah Sakit Dr. Hasan Sadikin Bandung}

Berdasarkan hasil observasi yang penulis lakukan, di RSUP Dr. Hasan Sadikin Bandung sudah ada Standar Operasional Prosedur (SPO) Pengembalian Rekam Medis. Prosedur pengambalian rekam medis rawat jalan :

1. Petugas pendistribusian memeriksa kesesuaian jumlah berkas rekam medis yang akan dikembalikan dengan form ekspedisi pengembalian.

2. Apabila berkas rekam medis yang akan di kembalikan sudah sesuai dengan form ekspedisi pengembalian baik dari segi jumlah dan isinya, maka petugas distribusi mengembalikan berkas rekam medis ke ruang penyimpanan sub instalasi pengelolaan rekam medis

3. Apabila berkas rekam medis yang akan di kembalikan tidak sesuai dengan form ekspedisi pengembalian baik dari segi jumlah dan isinya, maka petugas distribusi melakukan konfirmasi ulang ke petugas klinik

4. Petugas pendistribusian menyerahkan dan melakukan serah terima berkas rekam medis rawat jalan dengan petugas penyimpanan

Di dalam SPO pengembalian berkas rekam medis rawat jalan tidak dijelaskan berapa lama waktu pengembalian rekam medis rawat jalan. Lama waktu pengembalian rekam medis rawat jalan hanya di jelaskan pada panduan pelayanan instalasi rekam medis yaitu pengembalian berkas rekam medis rawat jalan segera setelah selesai pelayanan (Kristina, 2015). Menurut departemen kesehatan RI, Seseorang yang menerima / meminjam rekam medis, berkewajiban untuk mengembalikan dalam keadaan baik dan tepat waktunya. Dan harus dibuat ketentuan berapa lama jangka waktu peminjaman berkas rekam medis atau rekam medis berada diluar ruang penyimpanan rekam medis (Depkes RI, 2006).

\section{HASIL DAN PEMBAHASAN}

\section{A. Hasil Penelitian}

Berdasarkan pengamatan pengembalian rekam medis rawat jalan di RSUP Dr. Hasan Sadikin Bandung belum sesuai dengan prosedur. Dalam pengembalian rekam medis yang dilakukan oleh petugas poliklinik ke ruang filling tidak melalui tahap serah terima dan pengecekan oleh petugas yang berada di poliklinik, sehinga jumlah rekam medis yang dikembalikan tidak sesuai dengan yang ada di daftar jumlah kunjungan pasien.

Penelitian ini di lakukan di Rumah Sakit Dr. Hasan Sadikin Bandung Pada bulan Juni 2021 Dengan Hasil :

Tabel 1. Waktu pengembalian rekam medis rawat jalan RSUP Dr. Hasan Sadikin Bandung pada tanggal $2-30$ juni 2021

\begin{tabular}{|c|c|c|c|c|c|c|c|c|}
\hline \multirow{3}{*}{ No } & \multirow{3}{*}{ Tanggal } & \multirow{3}{*}{ Jumlah } & \multirow{2}{*}{\multicolumn{2}{|c|}{$\begin{array}{l}\text { Rekam Medis } \\
\text { Yang Kembali } \leq \\
\text { 1x24 jam }\end{array}$}} & \multirow{2}{*}{\multicolumn{2}{|c|}{$\begin{array}{l}\text { Rekam Medis } \\
\text { Yang Kembali } \geq \\
1 \times 24 \text { jam }\end{array}$}} & \multirow{2}{*}{\multicolumn{2}{|c|}{$\begin{array}{l}\text { Rekam Medis } \\
\text { Yang } \\
\text { Dipinjam }\end{array}$}} \\
\hline & & & & & & & & \\
\hline & & & Jumlah & $\%$ & Jumlah & $\%$ & Jumlah & $\%$ \\
\hline 1 & $\begin{array}{l}2 \text { juni } 2021 \\
\text { s/d } 14 \text { juni } \\
2021\end{array}$ & 50 & 13 & $63 \%$ & 30 & $80 \%$ & 7 & $57 \%$ \\
\hline 2 & $\begin{array}{l}15 \text { juni } \\
2021 \text { s/d } 30 \\
\text { juni } 2021\end{array}$ & 50 & 9 & $59 \%$ & 36 & $86 \%$ & 5 & $55 \%$ \\
\hline & Jumlah & 100 & 22 & $61 \%$ & 66 & $83 \%$ & 12 & $56 \%$ \\
\hline
\end{tabular}


Dari tabel satu didapat hasil persentase waktu pengembalian rekam medis rawat jalan selama 30 hari kerja ke instalasi rekam medis, persentase pengembalian rekam medis yang $\leq 1 \times 24$ jam sebesar $61 \%$ dan yang $\geq 1 \times 24$ jam sebesar $83 \%$. Pengembalian berkas rekam medis harus dilaksanakan tepat waktu. Apabila semakin banyak berkas rekam medis yang dikembalikan tepat waktu akan semakin cepat proses pengolahan dan pelaporan rekam medis (Muchtar et al., 2018). Sedangkan, jika berkas rekam medis semakin banyak yang tidak dikembalikan tepat waktu maka akan terjadi penumpukan berkas rekam medis dibagian pengerjaan dan pelaporan sehingga beban kerja petugas rekam medis akan semakin bertambah.

Dari hasi observasi serta wawancara dengan petugas rekam medis ada beberapa faktor yang menyebabkan keterlambatan pengembalian rekam medis rawat jalan di RSUP Dr. Hasan Sadikin yaitu terjadi penundaan pengembalian rekam medis oleh petugas poliklinik, pasien yang batal melakukan pemeriksaan rekam medis nya tidak segera dikembalikan, rekam medis dipinjam dr dengan tidak ada nya ekspedisi peminjaman, dan perawat lupa mengembalikan rekam medis karena ada rencana tindakan pada pasien tersebut

\section{B. Pembahasan}

Berdasarkan hasil data pada tabel 1. masih terdapat beberapa poliklinik yang mengembalikan berkas rekam medis rawat jalan lebih dari 1X24 jam. Artinya, masih ada sikap petugas poliklinik dan petugas pengembalian berkas rekam medis yang kurang baik atau yang masih belum patuh terhadap pengembalian berkas rekam medis rawat jalan hal ini dapat menyebabkan keterlambatan pengembalian berkas rekam medis rawat jalan, hal ini sejalan dengan Rusmala jika petugas bersikap kurang baik terhadap ketepatan pengembalian berkas rekam medis maka akan menghambat kegiatan selanjutnya yaitu assembling, koding, verifikasi klaim BPJS serta filing (Rusmala, 2016). Menurut Notoatmodjo dalam buku Promosi Kesehatan, sikap adalah juga respon seseorang terhadap stimulus atau objek tertentu, yang sidah melibatkan faktor pendapat dan emosi yang bersangkutan (senang-tidak senang, setuju-tidak setuju, baik-tidak baik dan sebagainya) (Notoatmodjo, 2019).

Dari hasil penelitian membuktikan bahwa pengembalian rekam medis rawat jalan di RSUP Dr. Hasan Sadikin pada tanggal 2-30 juni 2021 dari total 100 berkas rekam medis rawat jalan masih terjadi ketidaktepatan waktu pengembalian. Berkas rekam medis yang tidak tepat waktu sebesar 66 atau $83 \%$ berkas rekam medis dan yang tepat waktu sebesar 22 atau $61 \%$ berkas rekam medis. keterlambatan tertinggi terjadi pada tanggal $15-30$ juni 2021 yaitu 36 berkas rekam medis atau $86 \%$. Keterlambatan terendah terjadi terjadi pada tanggal $2-14$ juni 2021 sebanyak 30 berkas rekam medis atau $80 \%$. Ada batas waktu yang diatur dalam pengembalian rekam medis oleh individu yang menerima, sebaiknya pada akhir hari kerja. Rekam medis pasien pulang harus dikirim ke instalasi rekam medis sehari setelah pasien pulang (Handayani et al., 2021). Petugas rekam medis harus menindaklanjuti setiap poliklinik yang tidak mengembalikan rekam medis dalam jangka waktu yang sudah ditentukan (Janti \& Wariyanti, 2020).

Faktor - faktor yang menyebabkan keterlambatan pengembalian rekam medis rawat jalan yaitu terjadi penundaan pengembalian rekam medis oleh petugas poliklinik, pasien yang batal melakukan pemeriksaan rekam medis nya tidak segera dikembalikan, rekam medis dipinjam dari dengan tidak adanya ekspedisi peminjaman, dan perawat lupa mengembalikan rekam medis karena ada rencana tindakan pada pasien tersebut (Berkas, 2019).

\section{KESIMPULAN}


Penerapan pengembalian berkas rekam medis sudah diwajibkan melakukan tahap serah terima dan pengecekan oleh petugas yang berada diruang rekam medis, sehingga jumlah rekam medis yang dikembalikan dapat diketahaui kekurangan berkas rekam medis yang dikembalikan. Dan didapat Berkas rekam medis yang tidak tepat waktu sebesar 66 atau $83 \%$ berkas rekam medis dan yang tepat waktu sebesar 22 atau $61 \%$ berkas rekam medis. Keterlambatan tertinggi terjadi pada tanggal 15-30 juni 2021 yaitu 36 berkas rekam medis atau $86 \%$. Keterlambatan terendah terjadi pada tanggal 2-14 juni 2021 sebanyak 30 berkas rekam medis atau $80 \%$.

Faktor yang menyebabkan keterlambatan pengembalian rekam medis rawat jalan di RSUP Dr. Hasan Sadikin yaitu terjadi penundaan pengembalian rekam medis oleh petugas poliklinik, pasien yang batal melakukan pemeriksaan rekam medis nya tidak segera dikembalikan, rekam medis dipinjam dr dengan tidak ada nya ekspedisi peminjaman, dan perawat lupa mengembalikan rekam medis karena ada rencana tindakan pada pasien tersebut.

\section{BIBLIOGRAFI}

Berkas, P. (2019). Faktor Penyebab Keterlambatan Waktu Pengembalian Berkas Rekam Medis Rawat Inap Di Rs Estomihi Medan Tahun 2019.

Departemen Kesehatan RI Tentang Pedoman Penyelenggaraan Dan Prosedur Rekam Medis Rumah Sakit Di Indonesia, (2006).

Djusmalinar, D. (2017). Analisis Keterlambatan Pengembalian Berkas Rekam Medis Rawat Inap Ruang Seruni Ke Bagian Assembling Di Rumah Sakit Dr. M. Yunus Bengkulu Tahun 2017. Jurnal Manajemen Informasi Kesehatan (Health Information Management), 2(1), 1-7. https://doi.org/10.51851/jmis.v2i1.26

Handayani, E., Nur'ilmi, W., \& Sari, I. (2021). Analisis Pengembalian Rekam Medis Rawat Jalan Terhadap Kecepatan Pendistribusian ke Poliklinik Di RSAU Lanud Sulaiman. Cerdika: Jurnal Ilmiah Indonesia, 1(8), 939-946. https://doi.org/10.36418/cerdika.v1i8.152

Janti, H., \& Wariyanti, A. S. (2020). Kelebihan dan Kekurangan Penerapan Family Numbering System di Puskesmas Dinas Kesehatan Kota Surakarta. Jurnal Rekam Medis Dan Informasi Kesehatan, 3(1), 18-23. https://doi.org/10.31983/jrmik.v3i1.5554

Kristina, I. (2015). Tinjauan Keterlambatan Pengembalian Rekam Medis Pasien Pasca Rawat Inap di Rumah Sakit Mitra Keluarga Kelapa Gading. MEDICORDHIF Jurnal Rekam Medis, 2, 92.

Muchtar, R. D., Yulia, N., No, J. A. U., Kepa, D., \& Jeruk, K. (2018). Tinjauan Pengembalian Rekam Medis Rawat Jalan dan Kecepatan Pendistribusian Rekam Medis ke Poliklinik di Rumah Sakit An-Nisa Tangerang. Jurnal INOHIM, 5.

Muhammad Thabran Talib, S. (2021). Analisis pelaksanaan prosedur peminjaman berkas rekam medis di bagian penyimpanan rsud haji makassar. Journal perekam medis dan informasi kesehatan, 4(1), 1-8. https://doi.org/10.1234/jupermik.v4i1.54

Notoatmodjo, S. (2019). Promosi Kesehatan. Jakarta: Rineka Cipta.

Octaria, H., Jepisah, D., \& laili Fajhriah, N. (2021). Hubungan Disiplin, Keterampilan, Sikap Dan Pengetahuan Petugas Terhadap Kecepatan Pelayanan Pengambilan Berkas Rekam Medis Rawat Jalan Di Rsud Petala Bumi Pekanbaru 2020. JHMHS: Journal of Hospital Management and Health Science, 2(1), 89-99.

Permenkes, R. I. (2008). Peraturan Menteri Kesehatan Republik Indonesia No. 269/MenKes/Per/III/2008 tentang Rekam Medis. Jakarta: Kementerian Kesehatan $R I$.

Ritonga, Z. A., \& Wannara, A. J. (2020). Faktor-faktor Penyebab Keterlambatan Waktu 
Penyediaan Rekam Medis Rawat Jalan di Rumah Sakit Umum Madani Tahun 2019. Jurnal Ilmiah Perekam Dan Informasi Kesehatan Imelda (JIPIKI), 5(1), 85-97. https://doi.org/10.2411/jipiki.v5i1.341

Rusmala, A. . (2016). Hubungan Pengetahuan, Sikap Dan Perilaku Perawat Terhadap Ketepatan Waktu Pengembalian Rekam Medis Rawat Inap Di RSD Kota Tidore Kepulauan. Jurnal. Universitas Indonusa Esa Unggul.

Sugiyono. (2013). Metode Penelitian Pendidikan Pendekatan Kuantitatif, Kualitatif, dan R\&D. In Bandung: Alfabeta.

(C) 2021 by the authors. Submitted for possible open access publication under the cc) (D) (2) terms and conditions of the Creative Commons Attribution (CC BY SA) cc) license (https://creativecommons.org/licenses/by-sa/4.0/). 